\section{NF-кB RelA opposes epidermal proliferation driven by TNFR1 and JNK}

\author{
Jennifer Y. Zhang, Cheryl L. Green, Shiying Tao, \\ and Paul A. Khavari ${ }^{1}$
}

VA Palo Alto Healthcare System, Palo Alto, California 94305, USA; Program in Epithelial Biology, Stanford University

School of Medicine, Stanford, California 94305, USA

NF-кB inhibition promotes epidermal tumorigenesis; however, whether this reflects an underlying role in homeostasis or a special case confined to neoplasia is unknown. Embryonic lethality of mice lacking NF-кB RelA has hindered efforts to address this. We therefore generated developmentally mature $\operatorname{RelA^{-/-}}$ skin. $\operatorname{RelA}^{-/-}$epidermis displays hyperplasia without abnormal differentiation, inflammation, or apoptosis. Hyperproliferation is TNFR1-dependent because Tnfr1 deletion normalized cell division. TNFR1-dependent JNK activation occurred in $\mathrm{ReIA}^{-/-}$epidermis, and JNK inhibition abolished hyperproliferation due to RelA deficiency. Thus, RelA antagonizes TNFR1-JNK proliferative signals in epidermis and plays a nonredundant role in restraining epidermal growth.

Supplemental material is available at http://www.genesdev.org.

Received October 14, 2003; revised version accepted November 19, 2003.

Epidermal homeostasis requires a balance of pro- and antiproliferative signals; however, the genes mediating this process are incompletely understood. Recent work has shown that NF- $\kappa \mathrm{B}$ gene regulatory proteins can influence epidermal proliferation (Seitz et al. 2000a; Hinata et al. 2003). NF-кB can be activated by upstream IкB kinase (IKK) complex members and inhibited by ІкB proteins (Dixit and Mak 2002; Ghosh and Karin 2002). Inhibiting NF- $\kappa \mathrm{B}$, either via I $\mathrm{B} \alpha$ overexpression or pharmacologic mediators, leads to epidermal hyperplasia (Seitz et al. 1998; van Hogerlinden et al. 1999). Moreover, $\mathrm{NF}-\kappa \mathrm{B}$ signaling appears impaired in human epidermal cancer, and coexpressing $\mathrm{I} \kappa \mathrm{B} \alpha$ with oncogenic Ras is by itself sufficient to drive an uncontrolled epidermal proliferation that leads to invasive neoplasia (Dajee et al. 2003). It is therefore surprising that mice deficient in four of the five NF- $\kappa$ B subunits examined to date lack epidermis-intrinsic growth abnormalities (Kontgen et al. 1995; Sha et al. 1995; Weih et al. 1995; Franzoso et al. 1998). In addition, NF- $\mathrm{B}$ appears to be uninvolved in epidermal differentiation (Seitz et al. 1998; Hu et al.

[Keywords: Epidermis; NF-кB; proliferation; differentiation] ${ }^{1}$ Corresponding author.

E-MAIL khavari@CMGM.stanford.edu; FAX (650) 723-8762. Article and publication are at http://www.genesdev.org/cgi/doi/10.1101/ gad.1160904
2001), raising the possibility that NF- $\kappa B$ function may be entirely dispensable for epidermal homeostasis. NF- $\kappa \mathrm{B}$ proteins, however, display considerable genetic redundancy, and all five subunits are expressed in epidermis (Hinata et al. 2003). Moreover, homeostasis in adult epidermis deficient for the RelA/p65 NF- $\mathrm{kB}$ subunit has not been studied because of embryonic lethality (Beg et al. 1995), leaving open a potential role for RelA in this setting.

The 55-kD tumor necrosis factor cell surface receptor, TNFR1, is among the best-characterized inducers of NF$\kappa \mathrm{B}$ function. In addition to activating NF- $\kappa \mathrm{B}$ signaling via a cascade that includes MyD88, TRAF6, TAB2/TAK1/ $\mathrm{TAB}$, and IкB kinases (IKKs; Dixit and Mak 2002), TNFR1 engages other downstream effector pathways (Aggarwal 2000; Ghosh and Karin 2002). Among these are the c-jun $\mathrm{N}$-terminal kinase (JNK) mitogen-activated kinase protein pathway, which regulates cell death but has also been implicated in morphogenesis (Liu et al. 1996; Johnson and Lapadat 2002). Recent data suggest that NF- $\mathrm{B}$ subunits such as RelA can inhibit JNK function in several cell types in vitro (De Smaele et al. 2001; Tang et al. 2001; Reuther-Madrid et al. 2002); however, the importance of this cross-talk and whether it occurs in tissue have not been established.

Here we report that $\mathrm{Rel} \mathrm{A}^{-/-}$epidermis displays cellautonomous hyperproliferation independently of altered differentiation or inflammation. We know that increased cell division is accompanied by induction of epidermal JNK and requires TNFR1 because Tnfr1 deletion in this setting restored both proliferation and JNK levels to normal. The epidermal hyperplasia seen with NF-кB inhibition is blocked by pharmacologic and genetic interference with JNK activation. These findings indicate that RelA plays a nonredundant role in epidermal growth inhibition by opposing proliferative signals dependent on intact TNFR1 and JNK function.

\section{Results and Discussion}

To study the role of RelA in epidermal homeostasis, we generated developmentally mature $\mathrm{RelA}^{-/-}$skin tissue. Because these mice die by embryonic day 15.5 (E15.5) with massive liver apoptosis (Beg et al. 1995), we harvested $R e l A^{-/-}$embryo skin prior to that point and performed grafting to immune-deficient mice using established embryo skin surface grafting approaches (Oro et al. 1997). Grafted skin lacked RelA protein expression and was notable for marked hyperplasia, which remained stable over $8 \mathrm{wk}$ of analysis in vivo (Fig. 1A; Supplemental Fig. 1A). RelA ${ }^{+/-}$control tissue was similar to wildtype $\mathrm{RelA}^{+/+}$skin in every respect assessed. Hyperplasia in $R e l A^{-/-}$epidermis was due to increased cell division, as confirmed by a $>$ fourfold elevation in the epidermal mitotic index (Fig. 1B,C). Unlike epidermis lacking the upstream NF- $\mathrm{BB}$ regulator, IKK1/IKK $\alpha$ (Hu et al. 2001), or mice with epidermal ІкB $\alpha$ overexpression (Seitz et al. 2000b), RelA ${ }^{-/-}$mice lacked alterations in epidermal cell death, as assessed histologically and by TUNEL staining (Fig. 1A; Supplemental Fig. 1B). These findings indicate that epidermal RelA deficiency leads to increased proliferation without altering apoptosis. 


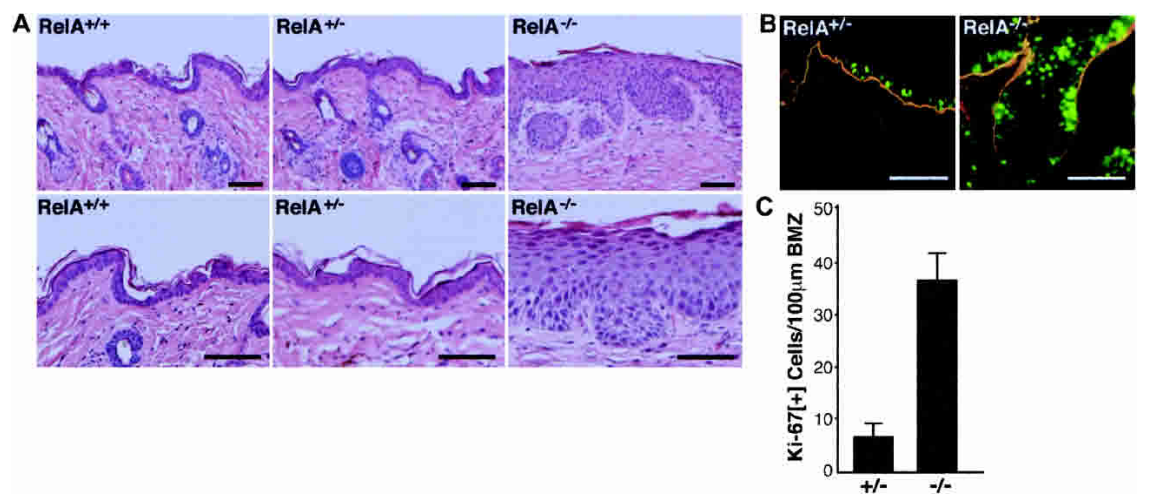

Figure 1. Hyperplasia and increased cell division in $R e l A^{-1-}$ epidermis. (A) Histologic appearance of $\mathrm{RelA}^{-1-}$ skin at $6 \mathrm{wk}$ postgrafting to immune-deficient mice. Note epidermal hyperplasia, moderately increased cell size, lack of inflammatory cell infiltrate, as well as normal granular and cornified layers in $R e l A^{-/-}$skin. Magnification in top panels, original $\times 10$, bottom panels $\times 20$, scale bars, $75 \mu \mathrm{m}$. $(B)$ Proliferation marker expression. Ki-67 (green), nidogen basement membrane zone (BMZ) marker (orange). Note the increase in Ki- $67^{+}$cells, including those located multiple cell layers above the BMZ; scale bars, $75 \mu \mathrm{m} .(C)$ Quantitation of numbers of proliferating cells/100 $\mu \mathrm{m}$ linear BMZ in RelA ${ }^{-/-}$epidermis versus control from three independent grafts \pm SD.

Epidermal differentiation can be altered in settings of increased proliferation but is not obligately linked to changes in cell division (Fuchs and Raghavan 2002). In tissue, RelA $A^{-/-}$epidermal cells expressed the differentiation markers keratin 10, involucrin, loricrin, and filaggrin in the appropriate suprabasal location (Fig. 2A), a finding consistent with the normal-appearing granular and cornified layers seen histologically in RelA ${ }^{-/-}$skin (Fig. 1A). RelA is therefore dispensable for normal differentiation, consonant with studies demonstrating that epidermal NF- $\mathrm{KB}$ blockade via IкB $\alpha$ fails to alter differentiation (Seitz et al. 2000b) and that IKK1 effects on differentiation proceed in an NF-кB-independent manner (Hu et al. 2001).

Epidermal hyperproliferation may occur as a secondary response to an influx of inflammatory leukocytes, as seen with conditional disruption of $I k k 2 / I k k \beta$ in epidermis (Pasparakis et al. 2002). RelA ${ }^{-/-}$tissue, however, lacked the F4/80[+] inflammatory dermal cell infiltrate, subcorneal epidermal pustules, and induction of inflammatory proteins such as IL-1 $\beta$, $\mathrm{TNF} \alpha$, and MCP-1 that characterize Ikk2 ${ }^{-1-}$ skin (Figs. $1 \mathrm{~A}$ and $2 \mathrm{~B}$ ). The absence of these indicators of inflammation suggests that hyperproliferation might be epidermal cell-autonomous. To test this, primary epidermal keratinocytes were purified from E14.5 embryos and cell proliferation kinetics was determined. RelA ${ }^{-/-}$keratinocytes exhibited enhanced proliferation (Fig. 2C). These findings indicate that RelA deficiency leads to epidermal cell-autonomous hyperproliferation.
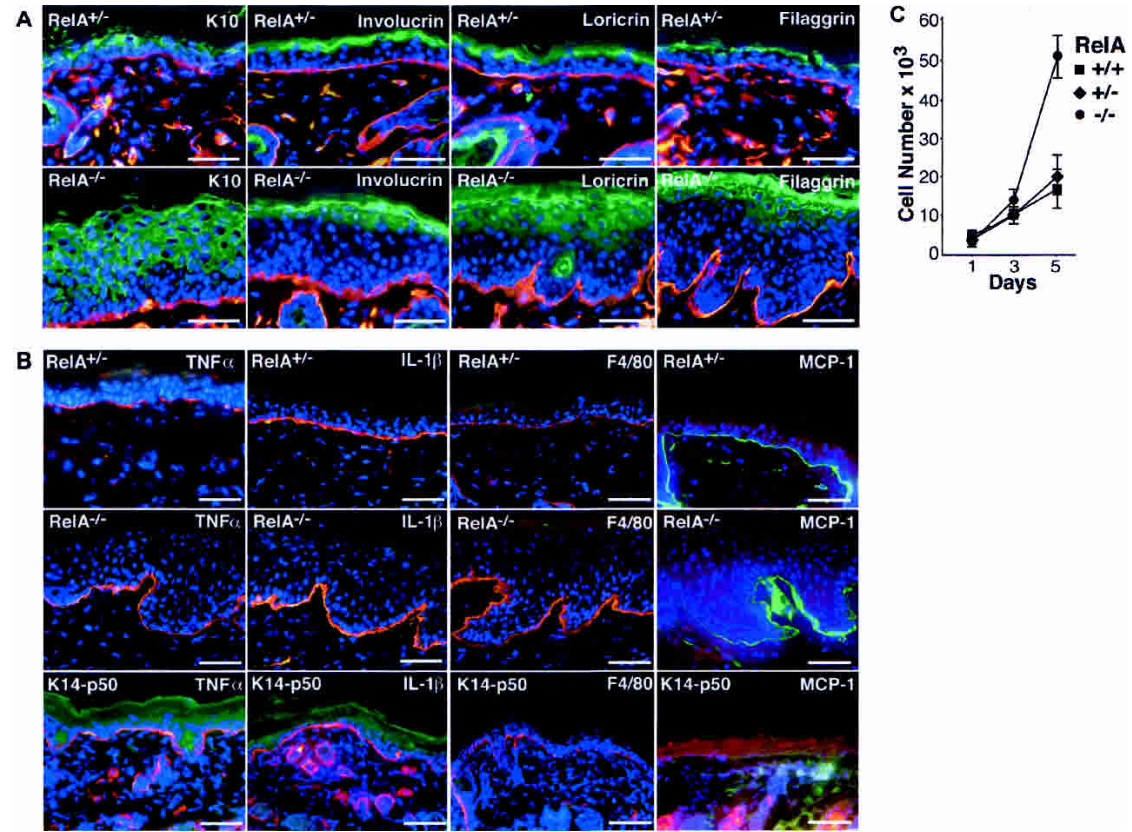

Figure 2. RelA $A^{-/}$epidermis displays normal differentiation proteins and lacks induction of proinflammatory cytokines. $(A)$ Expression of the differentiation markers K10, involucrin, loricrin, and filaggrin (green); laminin $5 \mathrm{BMZ}$ marker (orange); and Hoechst 3342 DNA stain (blue). Note the presence of differentiation proteins distributed normally to suprabasal epidermis in RelA $A^{-1-}$ tissue. Scale bars, $75 \mu \mathrm{m}$. (B) Lack of inflammation in RelA ${ }^{-/-}$skin. TNF $\alpha$, IL-1 $\beta$, and the F4/80 macrophage marker (green), laminin 5 (orange), and Hoechst 3342 (blue); last column, MCP-1 (red), BMZ marker nidogen (green). Note the lack of cytokine/chemokine induction or inflammatory cell infiltrate in $\mathrm{RelA}^{-/-}$epidermis compared with $\mathrm{RelA} \mathrm{A}^{+/-}$control. Previously generated transgenic mice expressing NF- $\mathrm{KB}$ p50 in epidermis via the keratin 14 promoter (K14-p50) represents a positive control for induction of TNF $\alpha$, IL-1 $\beta$, and MCP-1. Scale bars, $75 \mu \mathrm{m} .(C) R^{2} l A^{-/-}$keratinocyte-intrinsic hyperproliferation. Primary epidermal keratinocytes isolated from skin of E14.5 embryos were assessed for proliferative kinetics in vitro. Data represent triplicate independent experiments \pm SD for each genotype noted, with keratinocyte cell type confirmed by immunostaining of cells harvested at each time point with antibodies to keratin 14 . 


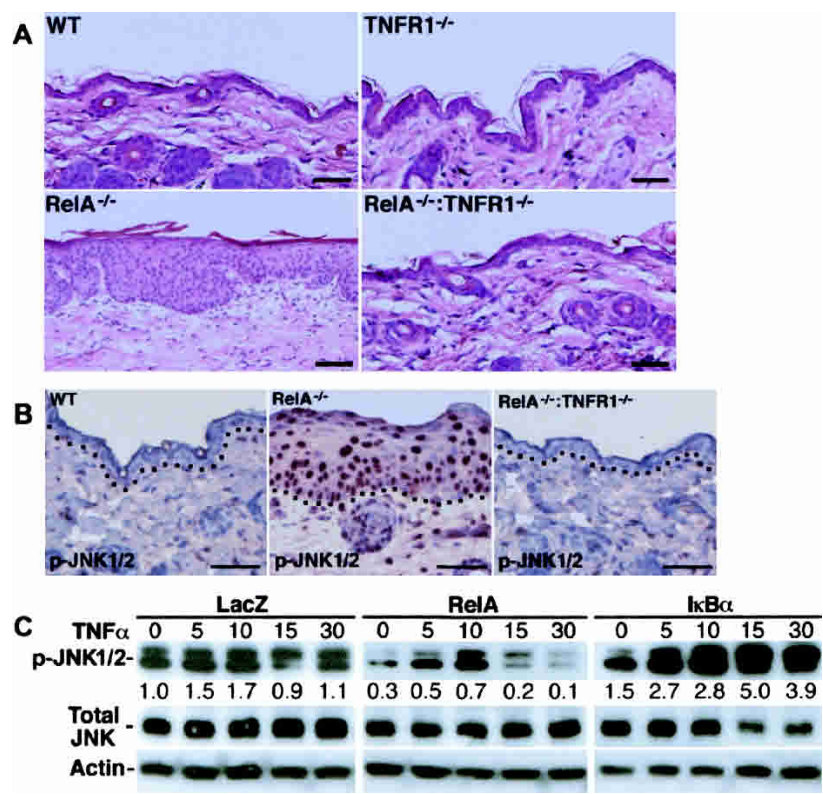

Figure 3. Increased epidermal proliferation due to RelA deficiency is TNFR1-dependent. (A) Histologic appearance of wild-type, Tnfr $1^{-/-}$, RelA ${ }^{-/-}$, and RelA $^{-/-}$Tnfr $^{-1-}$ skin 6 wk postgrafting to immunedeficient mice. Note hyperplasia in $\mathrm{RelA}^{-/-}$epidermis and its absence in $\mathrm{RelA}^{-1-}$ Tnfr1 ${ }^{-/-}$tissue. Scale bars, $75 \mu \mathrm{m}$. (B) Increased active JNK in $\mathrm{RelA}^{-1-}$ epidermis. Immunoperoxidase staining for phosphorylated active JNK1/2 (p-JNK1/2). Note intense nuclear detection of p-JNK1/2 in RelA ${ }^{-/-}$epidermis (brown staining) and restoration to the wild-type pattern in $\mathrm{RelA}^{-/-} \mathrm{Tnfr1}^{-/-}$tissue. Counterstaining was performed with hematoxylin; dotted line denotes BMZ. Scale bars, $75 \mu \mathrm{m} .(C)$ RelA decreases keratinocyte levels of activated JNK. Primary human keratinocytes transduced with retrovectors encoding LacZ control, RelA, or IкB $\alpha$. Cells were incubated $48 \mathrm{~h}$ posttransduction with TNF $\alpha(10 \mathrm{ng} / \mathrm{mL})$ for the number of minutes shown at the top of each lane. Proteins immunoblotted are noted at the right; optical densitometric quantitation is shown below each active phosphorylated JNK1/2 (p-JNK1/2) band, normalized to actin and total JNK control.

was designed to observe acute effects on active JNK levels and did not extend to studies of other subsequent processes, such as apoptosis, that are engaged in keratinocytes at later time points by TNF $\alpha$ in the setting of NF-кB hypofunction (Seitz et al. 2000a; Hinata et al. 2003). These data indicate that RelA growth effects are dependent on TNFR1 and that RelA antagonizes JNK activation in epidermal cells.

To determine if epidermal JNK induction is important for the hyperproliferation seen with NF-кB impairment, we next examined the effects of blocking JNK function on epidermal cell growth in this setting. In vitro, pharmacologic inhibition of JNK, but not MEK/ERK, abolished the keratinocyte hyperproliferation that occurs in both murine $R e l A^{-1-}$ keratinocytes and in human keratinocytes in which NF-кB has been inhibited by IкB $\alpha$ overexpression (Fig. 4A,B). Consistent with prior studies (Kock et al. 1990), murine keratinocytes express TNF $\alpha$ (Supplemental Fig. 2A), and inhibitory antibodies to TNFR1 but not TNFR2 also functioned in a fashion similar to JNK inhibitors (Fig. 4A). In human skin in vivo, JNK inhibition, by topical application of JNK inhibitor abrogated the epidermal hyperplasia and hyperproliferation seen in regenerated epidermis expressing Iк $\mathrm{B} \alpha$ (Fig. 4C-E). Because pharmacologic kinase inhibi- tors are known to lack complete specificity, we also expressed the dominant-negative JNK1-APF mutant (Derijard et al. 1994), and observed similar findings with this genetic approach to JNK disruption (Fig. 4C-E). Congruent with these human tissue findings, topical JNK inhibitor lowered the enhanced detection of phosphorylated c-jun seen in RelA-deficient murine epidermis back to the basal levels seen in wild-type tissue and reversed epidermal hyperplasia in vivo (Fig. 4F). This finding was accompanied by a normalization of the mitotic index in untreated RelA $A^{-1-}$ epidermis from $36.2 \pm 5.39$ down to $5.7 \pm 0.63$ with topical SP600125 JNK inhibitor, with wild-type control $6.1 \pm 1.44$. These findings confirm that interfering with JNK action abolishes the enhanced epidermal proliferation that occurs with NF- $\kappa$ B hypofunction.

Inhibiting the functions of NF- $\mathrm{BB}$ and its upstream IKKs can alter four major epidermal processes. These include apoptosis (deletion of $I k k 1$ and $N E M O / I k k \gamma$ as well as NF- $\kappa$ B blockade due to IкB $\alpha$ overexpression), dif-

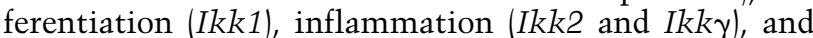
proliferation (deletion of $I k k 1, I k k 2, I k k \gamma$, as well as NFкB blockade with IкB $\alpha$; Seitz et al. 1998; Hu et al. 1999; Makris et al. 2000; Schmidt-Supprian et al. 2000; Hu et al. 2001; Pasparakis et al. 2002). Prior work demonstrating that hyperplasia in $I \mathrm{kk}^{-/-}$mice results from inflammation (Pasparakis et al. 2002), and that NF- $\kappa \mathrm{B}$ is dispensable for IKK1-mediated differentiation $(\mathrm{Hu}$ et al. 2001), might predict that RelA deficiency would have either predominantly inflammatory effects in epidermis or no effects at all. Recent work, however, suggested that NF-кB subunits exert primary epidermal growth effects by demonstrating that RelA induces growth inhibitory genes in epidermal cells but not other cell types (Hinata et al. 2003). In contrast to its oncogenic role in other settings, NF- $\mathrm{kB}$ may act as an important antiproliferative safeguard in stratified epithelium because its blockade facilitates uncontrolled neoplastic growth in both murine (van Hogerlinden et al. 1999) and human epidermis (Dajee et al. 2003). Of interest, NF-кB DNA-binding activity remains inducible in primary keratinocytes isolated from both $I k k 1^{-/-}$and $I k k 2^{-/-}$mice in response to stimuli such as TNF $\alpha$ (Hu et al. 2001; Pasparakis et al. 2002). Additionally, IKK-independent NF- $\kappa B$ target genes have been identified in cells deficient in IKK $\gamma$, IKK1, and IKK2 (Li et al. 2002). Therefore, the phenotypic changes in epidermis that result from the loss of individual upstream IKK subunits may not reflect complete impairment of NF-кB function.

The present work demonstrates that the effects of RelA deficiency are confined to keratinocyte proliferation. Although prior work had demonstrated that NF- $\mathrm{B}$ subunits, including RelA, inhibit keratinocyte growth (Seitz et al. 1998; Seitz et al. 2000a; Hinata et al. 2003), it was unclear whether this was an artifact of subunit overexpression or whether it reflected a potential physiologic role in epidermal growth regulation. The present findings indicate that RelA is required for homeostatic epidermal growth control. RelA $A^{-/-}$epidermis is altered downstream of IKK signaling and displays several important differences from $I k k 1^{-/-}$and $I k k 2^{-/-}$tissue. Although RelA deficiency leads to hyperplasia in a TNFR1dependent manner like $I k k 2^{-/-}$epidermis, it differs in lacking inflammation. Also, RelA ${ }^{-/-}$keratinocytes are hyperproliferative in culture, in contrast to $I k \mathrm{k}^{-/-} \mathrm{ke}$ ratinocytes, which are hypoproliferative (Pasparakis et 

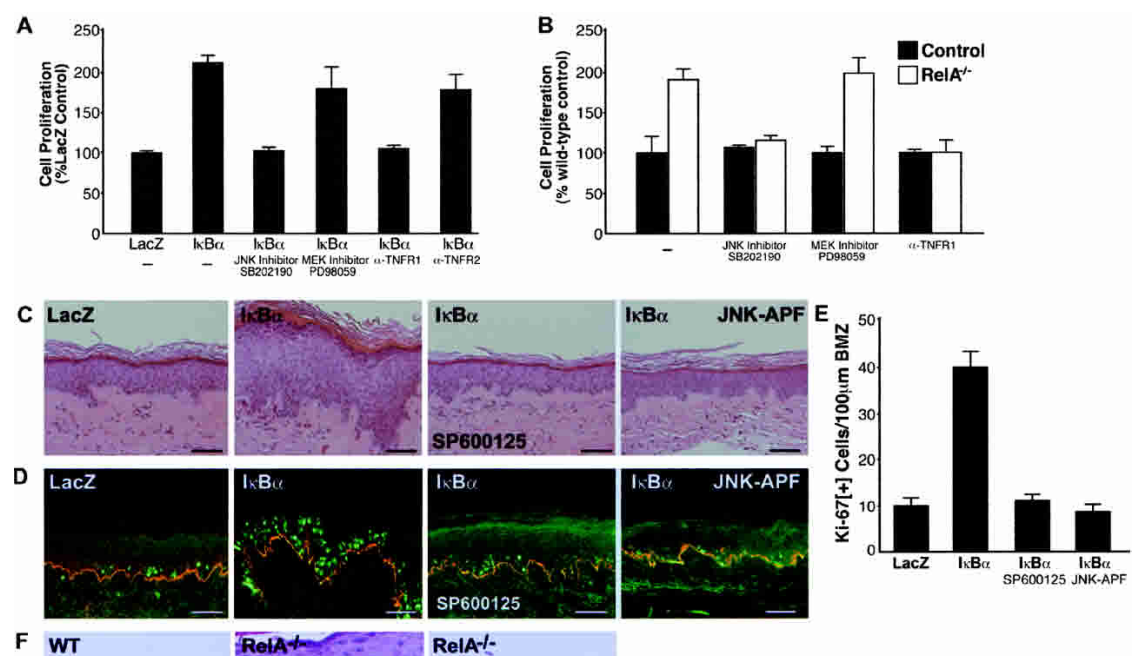

F WT

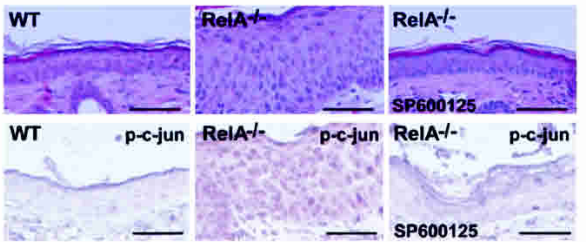

Figure 4. Intact TNFR1 and JNK function is required for epidermal hyperproliferation seen

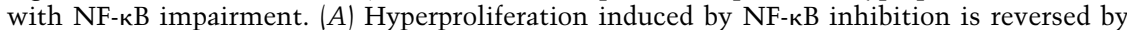
blockade of both TNFR1 and JNK. Primary human keratinocytes transduced with an IкB $\alpha$ retrovector were grown in the presence of the JNK inhibitor SB202190 (30 $\mu \mathrm{M})$, the MEK inhibitor PD98059 (30 $\mathrm{MM})$, and inhibitory antibodies to human TNFR1 and TNFR2. Cell numbers were determined $96 \mathrm{~h}$ later; in each case, data represent triplicate independent experiments $\pm S D$ and are normalized to LacZ-transduced control cells receiving identical treatment with the inhibitors and antibodies noted. $(B)$ Hyperproliferation of Rel $A^{-/-}$murine keratinocytes is inhibited by blockade of TNFR1 and JNK. Keratinocytes were isolated from skin of $R e 1 A^{-/-}$and $R e 1 A^{+/+}$E14.5 embryo siblings and incubated with antibodies to mouse TNFR1 and the inhibitors noted. Data represent triplicate independent experiments \pm SD. Cell numbers were determined after $96 \mathrm{~h}$ in culture and are normalized to untreated wild-type control. (C) Hyperplasia of human epidermis due to NF-кB blockade is abolished by JNK inhibition. Note the normalization of IкB $\alpha$-induced epidermal hyperplasia toward LacZ-marker-controlengineered tissue by topical JNK inhibitor (SP600125) application and by coexpression of dominant-negative JNK1 (JNK-APF). Scale bars, $75 \mu \mathrm{m}$. (D) Human tissues as in panel $C$; Ki-67 proliferation marker (green), type IV collagen BMZ marker (orange). (E) Mitotic index of epidermal tissue in vivo in numbers of proliferating cells/100 $\mu \mathrm{m}$ linear BMZ from three independent genetically engineered human skin grafts \pm SD. $(F)$ JNK inhibition reverses the hyperplasia and increased JNK substrate phosphorylation seen in RelA-/- epidermis. Histology (top panel) and immunostaining for phosphorylated c-jun (p-c-jun; bottom panel) are shown of wild type (left column), untreated RelA ${ }^{-/-}$skin (middle column), and RelA ${ }^{-/-}$skin treated with topical JNK inhibitor (SP600125; right column). Note the normalization of hyperplasia and p-c-jun detection in treated $R e l A^{-/-}$skin.

al. 2002). These differences could result from differential IKK2 induction of specific NF- $\mathrm{KB}$ subunits in epidermal cells, a dominant role for inflammatory effects in influencing subsequent proliferative capacity or a differing degree of subunit redundancy for inflammation versus proliferation. Consistent with the first possibility, IKK2 does not compensate entirely for abnormal RelA distribution in Ikk1 $1^{-1}$ epidermis (Takeda et al. 1999). Although similar to IKK1 deficiency in increased proliferation in vitro and apparent lack of inflammation, $\mathrm{ReIA}^{-/-}$ epidermal hyperplasia is stable for $8 \mathrm{wk}$ after grafting onto a wild-type background, in contrast to $I k k 1^{-/-}$epidermal grafts, which begin to lose their hyperplastic phenotype within 3 wk (Hu et al. 2001). This difference could result from a partial redundancy of IKK1 and IKK2 that may permit NF- $\mathrm{kB}$ growth control in Ikk1-/- epidermis in combination with paracrine factors, such as kDIF (Hu et al. 2001).
Our findings also suggest that opposing proliferative signals emanate from TNFR1 in epidermis. In an analogous fashion to pro- and antiapoptotic stimuli arising via TNFR1 in liver (Rosenfeld et al. 2000; Alcamo et al. 2001), JNK activation in the setting of RelA deficiency is associated with epidermal proliferation, whereas RelA is required for normal growth arrest. In contrast to the liver, where JNK induction promotes apoptosis, JNK deregulation due to NF-кB hypofunction in epidermis fails to trigger cell death but instead increases cell proliferation. Such a finding raises the prospect that TNFR1 may regulate epidermal proliferation through balancing pro- and antiproliferative signals mediated by pathways involving JNK and RelA, respectively. Recent studies in other cell types demonstrating that NF- $\mathrm{BB}$ inhibits $\mathrm{TNF} \alpha-$ mediated JNK activation and that IкB proteins up-regulate JNK activity are in agreement with this possibility (De Smaele et al. 2001; Tang et al. 2001; Reuther-Madrid et al. 2002). In summary, our data indicate that the RelA NF-кB subunit, although dispensable for epidermal differentiation, plays a nonredundant role in epidermal homeostasis and opposes hyperproliferation driven by TNFR1 and JNK.

\section{Materials and methods}

\section{Cell culture and gene transfer}

For murine keratinocyte studies, E14.5 embryo trunk skin was peeled and digested with $1 \times$ pancreatin and $0.25 \%$ trypsin (GIBCO BRL) for $2 \mathrm{~h}$ at $4^{\circ} \mathrm{C}$, followed by fine mincing, vortexing, and centrifugation. The cell pellet was resuspended in KSFM media (GIBCO BRL) supplemented with $0.09 \mathrm{mM}$ calcium. Cells were plated on collagen IV-coated plates for $1 \mathrm{~h}$, then washed twice and fed with fresh KSFM in the presence of 2.5 $\mathrm{ng} / \mathrm{mL}$ EGF, $10^{-10} \mathrm{M}$ cholera toxin, $5 \mathrm{ng} / \mathrm{mL}$ insulin, and $0.06 \mathrm{mM}$ calcium with or without neutralizing antibody to mouse TNFR1 (10 $\mu \mathrm{g} / \mathrm{mL}$; R\&D systems). For proliferation assays, cells were immunostained with primary antibodies against $\mathrm{K} 14$ to confirm keratinocytic origin. $\mathrm{K}^{+} 4^{+}$-positive cells were quantitated on a Zeiss Axiovert (OpenLab digital quantitation software, Improvision). Primary human keratinocytes were infected with retroviruses encoding LacZ, RelA, IкB $\alpha$ (Seitz et al. 1998; van Hogerlinden et al. 1999) or JNK1-APF (Derijard et al. 1994) in triplicate; >98\% gene transfer efficiency was verified in parallel by immunofluorescence staining. For proliferation assays, $8 \mathrm{~h}$ posttransduction, human cells were incubated with SB202190, PD05980 (Calbiochem), DMSO diluent control, or neutralizing antibodies to TNFR 1 or TNFR $2(10 \mu \mathrm{g} / \mathrm{mL} ; \mathrm{R} \& D$ systems) for 96 $\mathrm{h}$ then trypsinized for cell counting.

\section{Animal studies}

Following murine embryo genotyping at E14.5, embryonic skin grafts were generated on immune-deficient CB.17 scid/scid mice as described (Oro et al. 1997). Grafted $\mathrm{RelA}^{+/+}, \mathrm{RelA}^{+/-}$, and $\mathrm{RelA}^{-/-}$skin tissue ( $n=5$ independent embryos grafted/genotype) was analyzed via skin biopsies obtained at 6 to 8 wk postgrafting. Human epidermis was genetically engineered to express LacZ marker control, IкB $\alpha$, and dominant-negative 
JNK1 (JNK-APF) and grafted on immune-deficient mice $(n=5$ independent grafts per analyzed group) as described (Choate et al. 1996; Robbins et al. 2001). The topically permeant JNK inhibitor SP600125 (Bennett et al. 2001) was dissolved in dimethylsulfoxide and applied topically to human skin grafts $(1 \mathrm{mg} / \mathrm{d})$ for $7 \mathrm{~d}$ prior to biopsy and analysis. For JNK blockade studies in murine epidermis, SP600125 (1 mg/d) was topically applied under occlusion to indicated murine skin grafts for $1 \mathrm{wk}$, beginning 3 wk postgrafting.

Protein analysis

For Western blotting, $48 \mathrm{~h}$ posttransduction, cells were treated with TNF $\alpha$ (10 ng/mL; Sigma) for $0,7.5,15$, or $30 \mathrm{~min}$ and harvested for immunoblotting with antibodies against p-JNK1/2, total JNK (Cell Signaling), p65, IкB $\alpha$, or actin (Santa Cruz). For JNK kinase assays, primary human keratinocytes were pretreated with either dimethylsulfoxide diluent, the MEK-ERK inhibitor PD98059 (PD, $30 \mu \mathrm{M})$, or the inhibitors SB202190 $(30 \mu \mathrm{M})$ or SP600125 $(50 \mu \mathrm{M})$, which inhibit JNK kinase activity at this concentration range (Bain et al. 2003; Hayakawa et al. 2003), for $1 \mathrm{~h}$ prior to stimulation with $\mathrm{TNF} \alpha(10 \mathrm{ng} / \mathrm{mL})$ for $5 \mathrm{~min}$. Extracts were then harvested and immunoprecipitated with antibodies to JNK1/2, and kinase assays were performed using recombinant $\mathrm{c}$-jun substrate (Cell Signaling Technology). For immunostaining, 5- $\mu \mathrm{m}$ cryosections were fixed with cold methanol and blocked in $10 \%$ horse serum in PBS with $0.1 \%$ Tween- 20 for $30 \mathrm{~min}$ at room temperature. Fixed sections were incubated either with primary rabbit antibodies against mouse K10, involucrin, loricrin, filaggrin (BabCO), or MCP-1 (Santa Cruz) along with rat anti-mouse nidogen (Chemicon), or primary rat antibodies against mouse Ki-67 (DAKO), TFN $\alpha$, IL-1, or F4/80 (R\&D Systems) along with rabbit anti-mouse laminin 5 (gift of M.P. Marinkovich, Stanford University, Stanford, CA), followed by Cy2- or Cy3-conjugated secondary antibodies (Jackson ImmunoResearch). Activated JNK (p-JNK; Promega) was detected by immunoperoxidase staining of paraffin sections (Dajee et al. 2003). In human tissue, murine anti-Ki-67 (LabVision) was used with rabbit anti-collagen IV (CalBiochem) to double stain 5- $\mathrm{mm}$ cryosections.

\section{Acknowledgments}

We thank A.E. Oro, G.R. Crabtree, and M.P. Scott for helpful discussions and presubmission review as well as M. Karin (Stanford University, Stanford, CA) for RelA ${ }^{+/-}$and T. Mak for Tnfr1 ${ }^{+/-}$mice and R. Davis (Stanford University, Stanford, CA) for JNK1-APF. This work was supported by NIH grants AR45192 and AR43799.

The publication costs of this article were defrayed in part by payment of page charges. This article must therefore be hereby marked "advertisement" in accordance with 18 USC section 1734 solely to indicate this fact.

\section{References}

Aggarwal, B.B. 2000. Tumour necrosis factors receptor associated signalling molecules and their role in activation of apoptosis, JNK and NF-кB. Ann. Rheum. Dis. 59 Suppl 1: i6-i16.

Alcamo, E., Mizgerd, J.P., Horwitz, B.H., Bronson, R., Beg, A.A., Scott, M., Doerschuk, C.M., Hynes, R.O., and Baltimore, D. 2001. Targeted mutation of TNF receptor I rescues the RelA-deficient mouse and reveals a critical role for NF-KB in leukocyte recruitment. J. Immunol. 167: 1592-1600.

Bain, J., McLauchlan, H., Elliott, M., and Cohen, P. 2003. The specificities of protein kinase inhibitors: An update. Biochem. J. 371: 199204.

Beg, A.A., Sha, W.C., Bronson, R.T., Ghosh, S., and Baltimore, D. 1995. Embryonic lethality and liver degeneration in mice lacking the RelA component of NF-кB. Nature 376: 167-170.

Bennett, B.L., Sasaki, D.T., Murray, B.W., O'Leary, E.C., Sakata, S.T., Xu, W., Leisten, J.C., Motiwala, A., Pierce, S., Satoh, Y., et al. 2001. SP600125, an anthrapyrazolone inhibitor of Jun $\mathrm{N}$-terminal kinase. Proc. Nat1. Acad. Sci. 98: 13681-13686.

Choate, K.A., Medalie, D.A., Morgan, J.R., and Khavari, P.A. 1996. Corrective gene transfer in the human skin disorder lamellar ichthyosis. Nat. Med. 2: 1263-1267.

Dajee, M., Lazarov, M., Zhang, J.Y., Cai, T., Green, C.L., Russell, A.J., Marinkovich, M.P., Tao, S., Lin, Q., Kubo, Y., et al. 2003. NF-кB blockade and oncogenic Ras trigger invasive human epidermal neoplasia. Nature 421: 639-643.
Derijard, B., Hibi, M., Wu, I.H., Barrett, T., Su, B., Deng, T., Karin, M., and Davis, R.J. 1994. JNK1: A protein kinase stimulated by UV light and Ha-Ras that binds and phosphorylates the c-Jun activation domain. Cell 76: 1025-1037.

De Smaele, E., Zazzeroni, F., Papa, S., Nguyen, D.U., Jin, R., Jones, J., Cong, R., and Franzoso, G. 2001. Induction of gadd $45 \beta$ by NF-kB downregulates pro-apoptotic JNK signalling. Nature 414: 308-313.

Dixit, V. and Mak, T.W. 2002. NF- $\mathrm{kB}$ signaling. Many roads lead to madrid. Cell 111: 615-619.

Franzoso, G., Carlson, L., Poljak, L., Shores, E.W., Epstein, S., Leonardi, A., Grinberg, A., Tran, T., Scharton-Kersten, T., Anver, M., et al. 1998. Mice deficient in nuclear factor (NF)-к B/p52 present with defects in humoral responses, germinal center reactions, and splenic microarchitecture. J. Exp. Med. 187: 147-159.

Fuchs, E. and Raghavan, S. 2002. Getting under the skin of epidermal morphogenesis. Nat. Rev. Genet. 3: 199-209.

Ghosh, S. and Karin, M. 2002. Missing pieces in the NF-кB puzzle. Cell 109 Suppl: S81-S96.

Hayakawa, J., Depatie, C., Ohmichi, M., and Mercola, D. 2003. The activation of c-Jun NH2-terminal kinase (JNK) by DNA-damaging agents serves to promote drug resistance via activating transcription factor 2 (ATF2)-dependent enhanced DNA repair. J. Biol. Chem. 278: 20582-20592.

Hinata, K., Gervin, A.M., Zhang, J.Y., and Khavari, P.A. 2003. Divergent gene regulation and growth effects by NF- $\mathrm{kB}$ in epithelial and mesenchymal cells of human skin. Oncogene 22: 1955-1964.

Hu, Y., Baud, V., Delhase, M., Zhang, P., Deerinck, T., Ellisman, M., Johnson, R., and Karin, M. 1999. Abnormal morphogenesis but intact IKK activation in mice lacking the IKK $\alpha$ subunit of IкB kinase. Science 284: $316-320$.

Hu, Y., Baud, V., Oga, T., Kim, K.I., Yoshida, K., and Karin, M. 2001. IKK $\alpha$ controls formation of the epidermis independently of NF-кB. Nature 410: $710-714$.

Johnson, G.L. and Lapadat, R. 2002. Mitogen-activated protein kinase pathways mediated by ERK, JNK, and p38 protein kinases. Science 298: 1911-1912.

Kock, A., Schwarz, T., Kirnbauer, R., Urbanski, A., Perry, P., Ansel, J.C., and Luger, T.A. 1990. Human keratinocytes are a source for tumor necrosis factor $\alpha$ : Evidence for synthesis and release upon stimulation with endotoxin or ultraviolet light. J. Exp. Med. 172: 1609-1614.

Kontgen, F., Grumont, R.J., Strasser, A., Metcalf, D., Li, R., Tarlinton, D., and Gerondakis, S. 1995. Mice lacking the c-rel proto-oncogene exhibit defects in lymphocyte proliferation, humoral immunity, and interleukin-2 expression. Genes \& Dev. 9: 1965-1977.

Li, X., Massa, P.E., Hanidu, A., Peet, G.W., Aro, P., Savitt, A., Mische, S. Li, J., and Marcu, K.B. 2002. IKK $\alpha$, IKK $\beta$, and NEMO/IKK $\gamma$ are each required for the NF-к B-mediated inflammatory response program. $J$. Biol. Chem. 277: 45129-45140.

Liu, Z.G., Hsu, H., Goeddel, D.V., and Karin, M. 1996. Dissection of TNF receptor 1 effector functions: JNK activation is not linked to apoptosis while NF-кB activation prevents cell death. Cell 87: 565576.

Makris, C., Godfrey, V.L., Krahn-Senftleben, G., Takahashi, T., Roberts, J.L., Schwarz, T., Feng, L., Johnson, R.S., and Karin, M. 2000. Female mice heterozygous for IKK $\gamma /$ NEMO deficiencies develop a dermatopathy similar to the human X-linked disorder incontinentia pigmenti. Mol. Cell 5: 969-979.

Oro, A.E., Higgins, K.M., Hu, Z., Bonifas, J.M., Epstein, E.H., and Scott, M.P. 1997. Basal cell carcinomas in mice overexpressing sonic hedgehog. Science 276: 817-821.

Pasparakis, M., Courtois, G., Hafner, M., Schmidt-Supprian, M., Nenci, A., Toksoy, A., Krampert, M., Goebeler, M., Gillitzer, R., Israel, A., et al. 2002. TNF-mediated inflammatory skin disease in mice with epidermis-specific deletion of IKK2. Nature 417: 861-866.

Reuther-Madrid, J.Y., Kashatus, D., Chen, S., Li, X., Westwick, J., Davis, R.J., Earp, H.S., Wang, C.Y., and Baldwin Jr., A.S. 2002. The p65/RelA subunit of NF- $\mathrm{kB}$ suppresses the sustained, antiapoptotic activity of Jun kinase induced by tumor necrosis factor. Mol. Cell. Biol. 22: 8175-8183.

Robbins, P.B., Lin, Q., Goodnough, J.B., Tian, H., Chen, X., and Khavari, P.A. 2001. In vivo restoration of laminin $5 \beta 3$ expression and function in junctional epidermolysis bullosa. Proc. Natl. Acad. Sci. 98: 5193-5198. 


\section{Zhang et al.}

Rosenfeld, M.E., Prichard, L., Shiojiri, N., and Fausto, N. 2000. Prevention of hepatic apoptosis and embryonic lethality in RelA/TNFR-1 double knockout mice. Am. J. Pathol. 156: 997-1007.

Schmidt-Supprian, M., Bloch, W., Courtois, G., Addicks, K., Israel, A., Rajewsky, K., and Pasparakis, M. 2000. NEMO/IKK $\gamma$-deficient mice model incontinentia pigmenti. Mol. Cell 5: 981-992.

Seitz, C.S., Lin, Q., Deng, H., and Khavari, P.A. 1998. Alterations in NF- $\mathrm{kB}$ function in transgenic epithelial tissue demonstrate a growth inhibitory role for NF-кB. Proc. Natl. Acad. Sci. 95: 2307-2312.

Seitz, C.S., Deng, H., Hinata, K., Lin, Q., and Khavari, P.A. 2000 a. Nuclear factor $\kappa \mathrm{B}$ subunits induce epithelial cell growth arrest. Cancer Res. 60: 4085-4092.

Seitz, C.S., Freiberg, R.A., Hinata, K., and Khavari, P.A. 2000b. NF-кB determines localization and features of cell death in epidermis. J. Clin. Invest. 105: 253-260.

Sha, W.C., Liou, H.C., Tuomanen, E.I., and Baltimore, D. 1995. Targeted disruption of the p50 subunit of NF-к B leads to multifocal defects in immune responses. Cell 80: 321-330.

Takeda, K., Takeuchi, O., Tsujimura, T., Itami, S., Adachi, O., Kawai, T., Sanjo, H., Yoshikawa, K., Terada, N., and Akira, S. 1999. Limb and skin abnormalities in mice lacking IKK $\alpha$. Science 284: 313-316.

Tang, G., Minemoto, Y., Dibling, B., Purcell, N.H., Li, Z., Karin, M., and Lin, A. 2001. Inhibition of JNK activation through NF-кB target genes. Nature 414: 313-317.

van Hogerlinden, M., Rozell, B.L., Ahrlund-Richter, L., and Toftgard, R. 1999. Squamous cell carcinomas and increased apoptosis in skin with inhibited Rel/nuclear factor-кB signaling. Cancer Res. 59: 3299-3303.

Weih, F., Carrasco, D., Durham, S.K., Barton, D.S., Rizzo, C.A., Ryseck, R.P., Lira, S.A., and Bravo, R. 1995. Multiorgan inflammation and hematopoietic abnormalities in mice with a targeted disruption of RelB, a member of the NF-k B/Rel family. Cell 80: 331-340. 
Erratum

Genes \& Development 18: 17-22 (2004)

NF-KB RelA opposes epidermal proliferation driven by TNFR1 and JNK

Jennifer Y. Zhang, Cheryl L. Green, Shiying Tao, and Paul A. Khavari

Several affiliations in the Acknowledgments section of this paper were presented in error. M. Karin is affiliated with the University of California, San Diego; T. Mak is with the University of Toronto, Canada; R. Davis is with the University of Massachusetts Medical School; and A.E. Oro, G.R. Crabtree and M.P. Scott are with Stanford University. We apologize for any confusion this may have caused. 


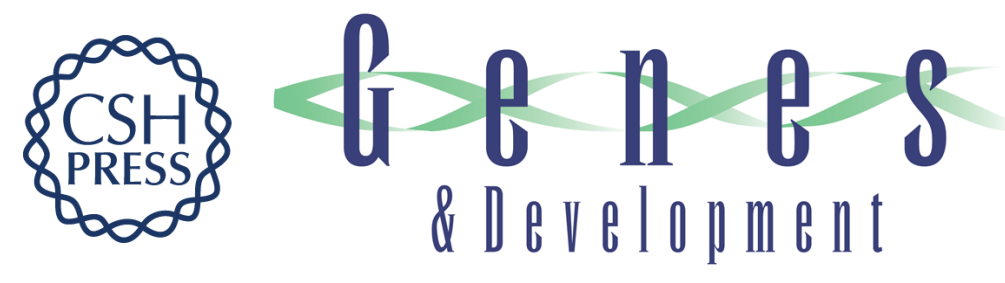

\section{NF-кB RelA opposes epidermal proliferation driven by TNFR1 and JNK}

Jennifer Y. Zhang, Cheryl L. Green, Shiying Tao, et al.

Genes Dev. 2004, 18:

Access the most recent version at doi:10.1101/gad.1160904

Related Content Errata for vol. 18, p. 17

Genes Dev. February , 2004 18: 461

References This article cites 36 articles, 17 of which can be accessed free at: http://genesdev.cshlp.org/content/18/1/17.full.html\#ref-list-1

Articles cited in:

http://genesdev.cshlp.org/content/18/1/17.full.html\#related-urls

License Email Alerting
Service $\begin{aligned} & \text { Receive free email alerts when new articles cite this article - sign up in the box at the top } \\ & \text { right corner of the article or click here. }\end{aligned}$

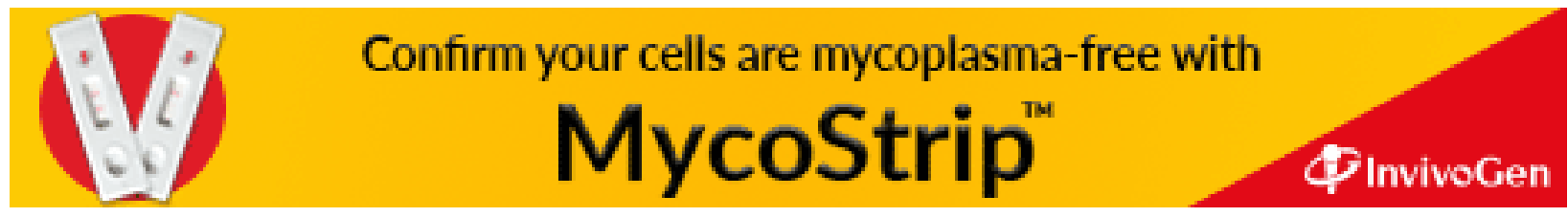

